\title{
Research on Performance Evaluation of Fresh Agricultural Products Supply Chain
}

\author{
Xiaoqian Wang \\ College of Information and Management Science \\ Henan Agricultural University \\ Zhengzhou, P. R. China \\ 953699623@qq.com
}

\author{
Dianli Cao \\ College of Information and Management Science \\ Henan Agricultural University \\ Zhengzhou, P. R. China \\ Caodianli6312@163.com
}

\begin{abstract}
With the increasing demand of fresh agricultural products, many scholars have paid more and more attention to the study of performance of fresh agricultural products supply chain. Based on the running effect, operating costs and service quality of fresh agricultural products supply chain, this paper establishes the performance evaluation index system. Then, the paper uses Analytic Hierarchy Process and Fuzzy Comprehensive Evaluation Method to construct a performance evaluation system. The empirical analysis shows that the method is effective.
\end{abstract}

Keywords- fresh agricultural products; performance evaluation; AHP; Fuzzy comprehensive evaluation method

\section{INTRODUCTION}

With the development of economy and the improvement of people's living standard, people pay more attention to fresh agricultural products. The supply chain of fresh agricultural product is a special supply chain which refers to vegetables, fruits, aquatic products, meat, poultry, eggs and other fresh agricultural products that are controlled in the appropriate temperature environment after harvest or catch or slaughter from producing area in order to guarantee the quality and safety and reduce the loss and prevent pollution in the links of product processing, transportation, storage, distribution and retail [1]. The performance evaluation of fresh agricultural products supply chain is based on the efficiency and operation of fresh agricultural products supply chain and the purpose of it is to evaluate the competitiveness and advantages and disadvantages of enterprises which are engaged in fresh agricultural products'supply chain.

At present, the performance evaluation of fresh agricultural products supply chain is in a fledging period in China. Lou Yongping [2] considers fresh agricultural products supply chain of Guangdong Province as a project in order to study systemically, establishes the evaluation index system of fresh agricultural products'supply chain in Guangdong Province which includes logistics service quality, efficiency of logistics distribution and logistics cost benefit, and then uses AHP method to evaluate. Sun Xiaomei [3] establishes performance evaluation system of fresh agricultural products'supply chain systematically, using fuzzy comprehensive evaluation method to combine the grey evaluation weight with degree of membership to fresh evaluate the performance of fresh agricultural products supply chain. Yang Jingjing [4] chooses thirty-three agricultural product logistics enterprises in Chengdu as samples, using SWOT method to analyze the present situation of agricultural product logistics in Sichuan Province, establishing the performance evaluation index system of agricultural products logistics. And then she uses questionnaires to collect data, applying principal component analysis to simplify the index system of the original, using DEA model to research empirically. Zhang Yongqi and Sun Hongling [5] analyze the feature of fresh agricultural products and logistics and combine the situation of fresh agricultural products' enterprises to establish the evaluation indexes, and then apply Fuzzy Comprehensive Evaluation Method to establish a feasible performance evaluation system.

\section{CONSTRUCT INDEX SYSTEM AND SELECT EVALUATION METHOD}

\section{A. Establish Fresh Agricultural Products Supply Chain Performance Evaluation Index System}

Fresh agricultural products supply chain is a complex system that covers the whole process of fresh agricultural products from the producer to the final consumer[6]. Based on it, this paper constructs the performance evaluation index system in terms of running effect, operation cost and service quality. At the same time, the paper uses qualitative indexes and quantitative indexes to select performance evaluation index (see Table I).

\section{B. Method and Theory}

This paper applies the Analytic Hierarchy Process (AHP) to determine the relative weight of each index, and then uses Fuzzy Comprehensive Evaluation Method to evaluate the performance of fresh agricultural products.

\section{- AHP}

Analytic Hierarchy Process is a method that considers the complicated multi-objective decision-making problem as a system and decomposes the target into multiple goals or standards and then decomposes them into multiple indexes of several levels to calculate the single order and the total order through the qualitative index fuzzy quantitative method in order to get a systematical approach for multiple optimization 
decision[7-8]. The procedure for using the AHP can be summarized as:

(1)Building the hierarchy structure of the system.

(2)Constructing comparative judgment matrix (see Table. II). Starting from the second layer of the hierarchical structure model, using paired comparison method and comparative scale to construct scaling comparative judgment matrix from the first layer to the bottom layer.

(3)Calculating order under single criterion and doing consistency test.

(4)Calculating the level of total order and doing consistency test.

TABLE $1 . \quad$ EVALUATION INDEX SYSTEM OF FRESH AGRICULTURAL PRODUCTS SUPPLY CHAIN

\begin{tabular}{|l|l|}
\hline Primary indicators & \multicolumn{1}{|c|}{ Secondary indicators } \\
\hline \multirow{4}{*}{ Running effect $A$} & On time delivery rate $A_{1}$ \\
\cline { 2 - 3 } & Inventory turnover rate $A_{2}$ \\
\cline { 2 - 3 } Operation cost $B$ & Inventory loss rate $A_{3}$ \\
\hline \multirow{5}{*}{ Service quality $C$} & Transportation cost $B_{1}$ \\
\cline { 2 - 2 } & Warehousing cost $B_{2}$ \\
\cline { 2 - 2 } & Transaction cost $B_{3}$ \\
\hline \multirow{5}{*}{ Customer satisfaction rate $C_{1}$} \\
\cline { 2 - 2 } & Product freshness rate $C_{2}$ \\
\cline { 2 - 2 } & Product quality qualified rate $C_{3}$ \\
\hline
\end{tabular}

TABLE II. COMPARATIVE JUDGMENT MATRIX

\begin{tabular}{|c|l|}
\hline Scale & \multicolumn{1}{c|}{ The meaning } \\
\hline 1 & $\begin{array}{l}\text { Compared two indicators, two indicators have the same } \\
\text { importance } \\
\text { Compared two indicators, one is a little important than } \\
\text { another } \\
\text { Compared two indicators, one is obvious important } \\
\text { than another } \\
\text { Compared two indicators, one is more important than } \\
\text { another } \\
\text { Compared two indicators, one is absolutely important } \\
\text { than another } \\
2,4,6,8 \text { respectively expresses the median of the } \\
\text { neighbor judgment 1-3, 3-5, 5-7, 7-9 }\end{array}$ \\
2,4, \\
6,8
\end{tabular}

- Fuzzy Comprehensive Evaluation Method

Fuzzy Comprehensive Evaluation Method is a comprehensive evaluation method that is based on fuzzy mathematics. According to membership degree theory, the method turns the qualitative evaluation into quantitative evaluation and makes an overall evaluation about things or object which is restricted by various factors. The procedure for using the Fuzzy Comprehensive Evaluation Method can be summarized as[9-10]:
(1) Determining factor set $F=\left\{f_{i}\right\}, \quad(i=1,2 . \mathrm{L}, n)$ and comment set $E=\left\{e_{j}\right\},(j=1,2 . \mathrm{L}, m)$.

(2) Counting and determining evaluation membership degree vector of the single factor and forming membership degree matrix $R$.

(3) Determining weight vector $W_{F}$ and numerical value of the weight evaluation set $W_{E}$.

(4) Calculating comprehensive evaluation vector by using

$$
S=W_{F} \cdot R \text {. }
$$

\section{POSITIVE ANALYSIS}

There is a vegetable base that supplies vegetable all over the country, specially for supermarkets. The base provides service in the link of picking, packing, transportation and marketing. Now, the paper uses the performance evaluation system built to analyze data of the base. The procedure can be summarized as: $1)$.

(1) Building the hierarchy structure of the system (see Fig.

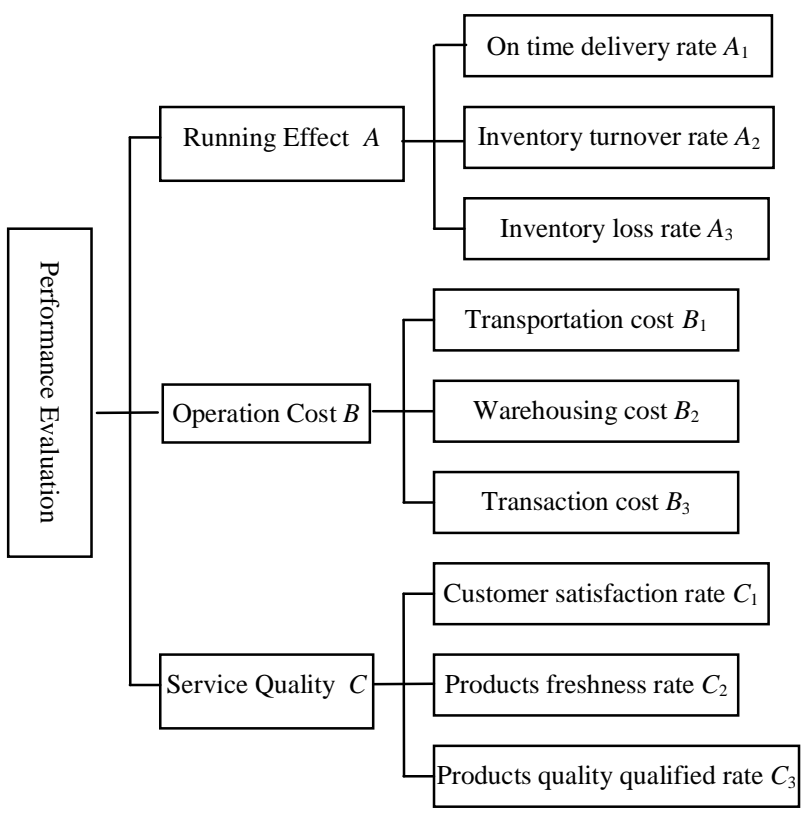

FIGURE I. THE PERFORMANCE EVALUATION MODEL OF FRESH AGRICULTURAL PRODUCTS

(2) According to comparative judgment matrix, the paper constructs scaling comparative judgment matrix and does consistency tests.

(3) Calculating the hierarchy total weight and doing consistency test (See Table III).

(4) Determining factor set an $F=\left\{A_{1}, A_{2}, A_{3}, B_{1}, B_{2}, B_{3}\right.$, 
$\left.C_{1}, C_{2}, C_{3}\right\}$ and comment set $E=\{$ very good, good, general, poor $\}$.

TABLE III. THE PERFORMANCE EVALUATION OF FRESH AGRICULTURAL PRODUCTS SUPPLY CHAIN

\begin{tabular}{|c|l|c|}
\hline $\begin{array}{c}\text { Primary } \\
\text { indicators }\end{array}$ & \multicolumn{1}{|c|}{ Secondary indicators } & $\begin{array}{c}\text { The total } \\
\text { weight }\end{array}$ \\
\hline \multirow{2}{*}{$\begin{array}{c}\text { Running } \\
\text { effect } A \\
(W=0.23)\end{array}$} & On time delivery rate $A_{1} \quad(W=0.105)$ & $W=0.024$ \\
\cline { 2 - 3 } & Inventory turnover rate $A_{2} \quad(W=0.258)$ & $W=0.059$ \\
\cline { 2 - 4 } & Inventory loss rate $A_{3} \quad(W=0.637)$ & $W=0.147$ \\
\hline \multirow{2}{*}{$\begin{array}{c}\text { Operation } \\
\text { cost } B\end{array}$} & Transportation cost $B_{1} \quad(W=0.592)$ & $W=0.384$ \\
\cline { 2 - 4 }$(W=0.648)$ & Warehousing cost $B_{2} \quad(W=0.333)$ & $W=0.216$ \\
\cline { 2 - 4 } & Transaction cost $B_{3} \quad(W=0.075)$ & $W=0.049$ \\
\hline \multirow{2}{*}{$\begin{array}{c}\text { Service } \\
\text { quality } C \\
(W=0.122)\end{array}$} & Pustomer satisfaction rate $C_{1}(W=0.149)$ & $W=0.182$ \\
\cline { 2 - 3 } & $\begin{array}{l}\text { Product quality qualified rate } C_{3} \\
(W=0.785)\end{array}$ & $W=0.096$ \\
\hline
\end{tabular}

(5) Determining evaluation membership degree vector of the single factor through Experts Grading Method and forming membership degree matrix $R_{A}, R_{B}$ and $R_{C}$.

$$
\begin{aligned}
& R_{A}=\left(\begin{array}{cccc}
0.36 & 0.56 & 0.08 & 0 \\
0.12 & 0.56 & 0.28 & 0.04 \\
0.2 & 0.60 & 0.2 & 0
\end{array}\right), \\
& R_{B}=\left(\begin{array}{cccc}
0.04 & 0.4 & 0.44 & 0.12 \\
0.08 & 0.44 & 0.48 & 0 \\
0.2 & 0.56 & 0.24 & 0
\end{array}\right), \\
& R_{C}=\left(\begin{array}{llll}
0.16 & 0.24 & 0.52 & 0.08 \\
0.12 & 0.32 & 0.48 & 0.08 \\
0.16 & 0.44 & 0.35 & 0.05
\end{array}\right) .
\end{aligned}
$$

(6) According to Formula (1), We can get

$$
\begin{aligned}
& S_{A}=(0.196,0.585,0.208,0.010) \\
& S_{B}=(0.065,0.212,0.438,0.071) \\
& S_{C}=(0.159,0.405,0.382,0.053), \\
& S_{\text {comprehensive evaluation vector }}=(0.107,0.321,0.378,0.055) .
\end{aligned}
$$

(7) According to the principle of maximum membership degree of fuzzy mathematics, the example can make a conclusion that $10.7 \%$ of people's comment is "very good", $32.1 \%$ of people's comment is "good", $37.8 \%$ of people's comment is "general" and $5.5 \%$ of the people's comment is "poor". As a result, the performance of fresh agricultural products' supply chain is in general level as a whole.

\section{CONCLUSION}

The paper builds the index system of fresh agricultural products supply chain, using AHP and Fuzzy Comprehensive Evaluation Method to evaluate the level of fresh agricultural products supply chain and then make a conclusion that the performance of fresh agricultural products supply chain in a vegetable base is in general level. This result is consistent with actual situation so the index system of this paper has the practical value. However, the paper has some disadvantages. Before building the evaluation system, the paper should use SWOT to analyze the situation of fresh agricultural products make sure that the study is more closely to actual situation. At the same time, quantitative indicators selected in the evaluation system is a little less. Moreover, the paper is a little subjective because it processes data by using AHP and Fuzzy Comprehensive Evaluation Method. As a result, how to reduce subjectivity in the paper will be a new research direction.

\section{ACKNOWLEDGMENT}

This research is supported by the Soft-science Foundation of Henan Province (No.102400440025; 102400440036).

\section{REFERENCES}

[1] N.Zuo."Research on Supply Chain Management of Supermarket Fresh Agricultural Products Based on Direct Procurement", Jinan University, 2009

[2] Y.P. Lou, "Building project of fresh agricultural products logistics system in Guangdong Province". North China Electric Power University, 2009.

[3] X.M.Sun, "Research on Supply Chain Performance Evaluation of Fresh Agricultural Products", Dalian Maritime University, 2012.

[4] J.J.Yang, “ The agricultural products logistics performance evaluation of Chengdu city", Sichuan Agricultural University, 2009.

[5] Y.Q.Zhang, H.L.Sun, "Research on Performance Evaluation System of Fresh Agricultural Product Logistics Enterprises" , Logistics Technology, pp. 168-174, August 2008.

[6] X.M.Fan, L.Z.Wang, G.P.Li, H.X.Wang, "Study on Performance Evaluation System of Fresh Agricultural Products Logistics System in Changchun city”, Productivity Research, pp. 108-111, July 2012.

[7] Y.L. Wang, Systems engineering, Beijing : Mechanical Industry Press, 2012.

[8] M.W.Dong, Z.L.Zhou, "Studies on Suppliers' Selection Evaluation System based on Hierarchy Analysis", Journal of Wuhan University of Technology(Information \& Management Engineering).

[9] Z.T.Wang, Systems engineering, Beijing: Peking University Press, 2010.

[10] Z.D,Lu, J.Lu, "Studies on Performance of "Farmer-Supermarket Direct Supply" in Hebei Province based on Fuzzy Comprehensive Evaluation", Journal of Agricultural Science and Technology, April 2013. 